\title{
Monitoring and Measurement of Digital Inclusion: A Critical Analysis of Key Global Frameworks
}

\author{
Morten Meyerhoff Nielsen \\ United Nation University, Operating Unit on Policy Driven Electronic Governance \\ meyerhoff@unu.edu
}

\begin{abstract}
Taking up the challenge laid down by the HighLevel Panel on Digital Co-operation to develop a global framework for measuring digital inclusion, this paper analyses ten current international and national attempts to measure and monitor digital inclusion. Two key questions are asked: What indicators of digital inclusion or inequality exist in current international initiatives? What, if any, are the weaknesses of current indicators to support strategic and practical decision making facilitating digital inclusion? Collectively the ten initiatives include 303 indicators, with access, (127 indictors), skills (62), use (50) and supporting environment (29) emerging as dominate clusters. Skills related to the digital age such as digital competence, critical thinking, innovation and entrepreneurship are limited. Sup-porting elements such as financial inclusion, online identification, security and trust are largely missing. Focus is on country level data and comparisons. User specific and geographical segmentation of indicators is rare thus limiting their value to decision makers in pinpointing areas, communities and individuals at risk of digital exclusion.
\end{abstract}

\section{Introduction}

Building on past industrial revolutions, current technology developments are changing the way people live, how society functions and how economies operate. Primarily differentiated by the pace of technological breakthroughs, the digital transformation of society is all-encompassing. The rapid pace of digital technology evolution has increased the awareness of interdependencies and the risk of greater social fragmentation $[15,23,38,39,48$, 60]. Despite increased opportunities, access and use of digital infrastructure and tools remains uneven. The COVID-19 pandemic is accelerating this process further and is amplifying past patterns, including socio-economic and digital divides [21, 29, 51, 62].
It is a collective responsibility to maximize the positive impacts of the digital transformation and manage the negative ones. Failing to address the negative impacts of digital transformation, the marginalisation of entire communities and, disproportionately, people already marginalised, is a real risk. Particularly vulnerable are low-income countries, such as small island states in the Caribbean and Pacific, as well as middle-income countries in Africa, the Americas, Asia, and the Middle East [3, 33, $40,42,52]$. If digital inclusion is not successfully addressed, the full benefit of technology cannot be reaped. In fact, there are already signs of the traditional path towards economic development increasingly closing, particularly in emerging economies [8].

Unequal access to online content and services has been a topic of debate in political, social, economic, and educational forums since the mid-1990s [31, 34]. As a catch-all phrase, "digital inclusion" includes financial, social and political inclusion in a digital context. Reference is often made to equality and equity in relation to access to education, healthcare, jobs and employment, public and private services, and even decision-making and influence in political spheres $[10$, 47].

While the two expressions digital divide and digital literacy are commonly used, the term digital inclusion is still relatively new. Digital inclusion is an objective. This means that if an individual is not digitally included, they are by default excluded, or at best marginalised. The digitally marginalised are individuals and communities within a given context who are subjected to inequalities as a result of the lack of access to digital infrastructure and tools. Their marginalisation, or exclusion, tend to be a result of location, age, gender, skills and/or affordability [3, 31, $46,50]$. Thus, digital inclusion and digital exclusion are two sides of the same proverbial coin.

Moving from the current info-industrial society to a digital one not only entails new technologies, but new concepts and ways of organising and producing value within society and the economy. The United 
Nations (UN) 2030 Sustainable Development Goals (SDGs) are not only a universal call to action to end poverty, protect the planet and ensure that all people enjoy peace and prosperity by 2030 [54]. The equal access and inclusion of all communities in an everincreasing digital society is a vital cross-cutting theme of the SDG Agenda [54].

In light of the UN 2030 SDGs, the UN SecretaryGeneral, Mr Guterres has called for an "...urgent and open debate between governments, the private sector, civil society and others on how we move forward together safely in the age of digital interdependence." [32] To support improved digital equality for traditionally marginalised communities, the Melinda Gates and Jack Ma led High-Level Panel, emphasises the need to develop a set of monitoring and measurement mechanisms [32]. An analysis of the impact of digital transformation of service delivery on children and youth [45], and a systematic review of several hundred peer reviewed publications on digital literacy and the digital gender divide published since 2010, have both come to similar conclusions [41]. Two key recommendations were made by the HighLevel Panel. First, that organisations across all sectors adopt specific policies to support digital inclusion and digital equality for women and traditionally marginalised groups and communities $[8,24,50]$. Second, to actively facilitate the inclusion of individuals, who within a given context are subjected to inequalities through a lack of access to digital infrastructure and tools as a result of location, age, gender, skills and/or affordability [4, 31, 32, 36, 56].

Globally multiple attempts to measure and monitor various aspects of inclusion exists. This includes socio-economic measurement initiatives such as International Telecommunication Union's (ITU) ICT Development Index (IDI) [27]. UNDP Global Multidimensional Poverty Index (MPI) [55] which in

\footnotetext{
${ }^{1}$ This paper is partially based on research conducted by the author in relation to the "Measuring the margins: A global framework for digital inclusion" Project for the Digital Future Society (DFS). The original research is a result of the DFS transnational initiative of Mobile World Capital Barcelona and Red.es, plus the project "SmartEGOV: Harnessing EGOV for Smart Governance (Foundations, methods, Tools)/NORTE-01-0145-FEDER-000037", supported by Norte Portugal Regional Operational Programme (NORTE 2020), under the PORTUGAL 2020 Partnership Agreement, through the European Regional Development Fund (EFDR).

${ }^{2}$ Part of the original research was carried out "Measuring the margins: A global framework for digital inclusion" Project by UNU-EGOV and DFS. The author would like to acknowledge and thank the core team of Dr. Mercy E.
}

turn is linked to the Human Development Index (HDI) [25], Gender Social Norms Index (GSNI) [17], and spin-offs like the Gender Inequality and COVID-19 Crisis [16]or Global Preparedness and Vulnerability [20]dashboards. Other initiatives focus on a specific or diverse population segments. For instance, the Digital Accessibility Rights Evaluation (DARE) Index [9] focus on the inclusion and rights (incl. digital rights and inclusion) of persons with disabilities [9], or the UNICEF lead Global and EU Kids Online initiatives $[14,19]$. The Ranking Digital Rights (RDR) and the Corporate Accountability Index (CAI) [46] by contracts assesses the twenty most influential telecommunications companies and internet platforms in relation to their commitments to corporate responsibility, transparency, freedom of expression, privacy and data protection.

Taking up the challenge laid down by the HighLevel Panel on Digital Cooperation to develop a global framework for measuring digital inclusion, this paper analyses ten past and current international attempts to measure and monitor digital inclusion as the digital transformation of society gathers pace. In doing so, this paper ${ }^{1}$ attempt to answer two key research questions:

- RQ1 - What, if any, indicators of digital inclusion or inequality are used in key global measuring initiatives?

- RQ2 - What, if any, are the weaknesses of current indicators to support strategic and practical decision making facilitating digital inclusion?

\section{Methodology}

To explore the topic, this paper $^{2}$ applies an exploratory, qualitative, case study methodology

Makpor and Joana Carvalho, plus Dr. Judy Backhouse, Nichole Harper and not least Carina Lopes for their reviews and ongoing contributions to the original research. The original research was carried out by core team of three people with degrees and backgrounds in economics, political science, innovation, and technology. The core team was complimented by one internal and two external reviewers with complimentary backgrounds. Half the team members have $\mathrm{PhD}$ degrees, the other half have master's degrees. All team members have worked in international and regional think tanks with half also having worked in both academia, the public and private sectors. All but one team member has worked and lived in more than three countries on at least two continents for an extended period. The author of this paper was the 
which enables both case analysis and cross-case comparison [7, 63]. Before choosing which international and national initiatives, measuring digital inclusion, to be analysed for this research, it is important to remember that for any statistical measure or indicator to be of value for decision makers they must ideally be quantifiable, practical, directional, actionable and even financial. In short, an indicator must have six essential characteristics [8, 22, 26]. First, it must be valid (i.e. measuring what they claim to measure). Second, it must be relevant to the problem at hand. Third, it should be easy to measure. Forth, it should allow for both aggregation and disaggregated by user-segments and geography. Fifth, a measure should be based on either a quantification or a judgement within an organisation or outside, such as audits and benchmarking but must be quantifiable and measurable over time, in either or an aggregated or a disaggregated form. Sixth, a measure should provide decision makers with a snapshot of the current state of affairs on which they can base their decisions [8, 22, 26].

Globally, the indicators in at least ten initiatives measuring digital inclusion have the six characteristics outlined above. These initiatives were identified through a semi-structured online search, in English, using single and combined keywords and keyword strings, incl. inclusion, exclusion, marginalised, online, digital, internet, IT, ICT, index, benchmark, survey, data, statistics. Single reports, or datasets covering only a single year were excluded.

The ten cases identified have all been measuring digital inclusion over multiple years. Similarly, all ten claim to cover all inhabitants in the countries they cover, i.e. do not focus on a single population segment. Although it excludes interesting initiatives like the DARE Index [9] or the international, global and national variations of Kids Online [14, 19] his feature was deemed important as digital inclusion, or the degree of potential exclusion, is not necessarily the result of a single factor such as geographical location, gender, age, educational or income level, type of potential disabilities. Of the initiatives identified all but one initiative also stands out in terms of geographical coverage, and number and relevance of indicators covered.

Chosen for analysis are five initiatives are from international or regional organisations (i.e. IDI, III, DESI, NRI, EGDI see next section for full names and details) covering between 31 (DESI) and 193 (EGDI) countries. Four are conducted by civil society or private sector organisations (MIC, GII, GCI, ADI),

senior expert, team leader and project manager responsible for the original research project. and one cover a single country (i.e. DII) covering between 60 (ADI) and 165 (MIC), while the one cover 20 international companies with a global presence ( While multiple national initiatives to measure digital inclusion, e.g. Brazil's ICT Household or Sweden's Barn and Internet (Children and Internet) surveys, the Australian DII was deemed interesting for its similarities with the European DESI covering 31 countries. Combined the ten cases represent an interesting and varied sample.

For the case analysis, indicators used in the ten cases were compared in a mapping exercise to identify homogeneity or heterogeneity followed by a qualitative metasynthesis analysis [13, 49]. The ten cases chosen are outlined in section 3 and analysed in section 4 .

\section{Ten key measurement initiatives including digital inclusion}

Of the ten cases selected, five are international initiatives. The largest of these by coverage and number of indicators, is the ITU ICT Development Index (IDI) ${ }^{3}$ [27]. The ITI evaluates 176 countries on an annual basis from a national perspective around three clusters: access to, affordability and quality of infrastructure; skills and competences, and actual usage of ICTs, specifically fixed and mobile telephony, and internet. Second, the World Economic Forum has for over four decades compared 130 countries in its annual Global Competitiveness Report (GCR) [59]. Of particular relevance to digital inclusion are the pillars on ICT adoption and skills. Also of relevance is the complimentary Global Information Technology Report on Networked Readiness benchmark and its sub-indexes on readiness and usage. The Inclusive Internet Index (III) [30] measures access to and the use of the internet in over 80 countries. The annual Digital Economic and Society Index (DESI) [28] is by indicators the second largest, but not by geographical coverage. It is based on the yearly Eurostat ICT Usage in Households and Individuals survey. The DESI cover 31 European countries and is a major source of information for monitoring efforts to promote a single European information space, an inclusive knowledge-based society, and quality of life. Like the ITI, GCR and III it covers access, but also skills and usage. DESI indicators are broken down in relation to access points (i.e. home vs. work) and technologies (i.e. fixed vs. mobile internet and telephony), access devices (i.e.

\footnotetext{
${ }^{3}$ Note, the IDI is formally known as the Digital Access Index (DAI): http://www.itu.int/ITU-D/ict/dai/.
} 
computer vs. mobile), categories of usage (e.g. eCommerce, eBanking, eGovernment services, types of software usage), and frequency of use (i.e. daily, quarterly, annually). With respect to inclusion, a number of the DESI indicators are segmented in relation to country, regions (optional), gender, age, income, educational attainment level, and even type of employment (i.e. blue- vs white-collar work). The Network Readiness Index (NRI) from the World Economic Forum (WEF) cover 136 countries. By comparison, UNDESA's biannual E-Government Development Index (EGDI) [11, 12], covers 193 countries and economies and thus covers more countries than any other. The EGDI does not cover specific types or categories of users or communities but does have a general focus on digital inclusion. Specifically the sub-indexes include access to telecommunication infrastructure (i.e. the Technology Infrastructure Index), human capacities and skills (i.e. the Human Capacity Index), online service and various means of individuals to engage with the public sector for service requests (i.e. the Online Service Index) or consultation and participation in various forms of decision making (i.e. the E-Participation Index) but these focus on the availability of information, data and services rather than use.

Private organisations, civil society and academia also collect data in relation to digital inclusion. Based on their geographical coverage and the number of indicators four initiatives are of particular interest in relation to the monitoring and measurement of digital inclusion. The GSMA State of Mobile Internet Connectivity (MIC) [53] is based on data from 165 countries and includes indicators such as internet access, the quality and affordability of access, technology types, skills of users, gender equality, eGovernment and cyber-security readiness of the public sector. The Global Innovation Index (GII) [18] looks at 140 countries in relation to different factors related to innovation including access to technology, skills and supporting environment. The Global e-Sustainability Initiative in its Global Competitiveness Index (GCI) [59] analyses 129 countries in relation to the human skills and factors behind innovation and policy creation. Of relevance to digital inclusion is the GIIs two sub-indexes on infrastructure, and human capital and research. The annual Affordability Drivers Index (ADI) [2] from the Web Foundation's Alliance for Affordable Internet asses and ranks around 60 southern hemisphere countries on the availability, access and affordability of the internet.

While the focus of this paper is on global and regional initiatives that measure and monitor digital inclusion, it should be note that national statistical agencies are the source of much data used in the global measurement frameworks. Unfortunately, many do not segment data and only a few have digital inclusion matrixes. Similar to the European DESI, the Australian Digital Inclusion Index (DII) [5] break indicators down in relation to gender, age, income and educational attainment level, and is chosen for this analysis. By comparison, the Digital Inclusion Index: A Measurement of ICT Advancements in Bahrain \& GCC [37] focuses solely on access to technology, including fixed and mobile telephony and Internet, with no segmentation in terms of user groups.

\section{Analysis}

\section{Current indicators of digital inclusion or inequality used in key global measuring initiatives?}

From the ten cases analysis, it is evident that digital inclusion is largely measured in terms of the internet and associated technologies. Combined, the case analysis identified 303 indicators across ten initiatives. The highest number of indicators in a single initiative is 44 in the DESI and 40 in the III (note, only includes relevant criteria). This is not only reflected in the weights given to the access cluster, but in the number of indicators. In a qualitative metasynthesis analysis [13, 49] four key clusters of indicators stood out, that is: Access issues such as access to technology, access point and quality of internet, digital devices, and even electricity to charge such technologies; traditional skills like reading, writing, mathematics, average years of education, but also STEM and digital literacy; supporting environment such as affordability, trust and security; use of digital tools and content such as internet use, activity types such as eBanking, eCommerce, or use of government services or social media. Clustering the 303 individual indicators (see figure 1) found in the ten initiatives, 286 relates to the four clusters identified in the metasynthesis analysis, that is 'access' (127 indictors), 'skills' (62), 'use' (50) and 'supporting environment' (47) of which the majority focus on affordability (i.e. 19 of 47). The conceptual frameworks applied in the ten cases, and even the rationales and titles underline this observation. The emphasis of Internet connectivity and access is likely the legacy of digital inclusion first appearing in public policy discourse in the wake of internet roll-out in the late 1990s [24]. The indicators (17) which could not be matched to the four clusters of indicators identified in the metasynthesis were related to data segmentation specifically gender (7), or other elements.

In relation to the different clusters, the main emphasis is clearly on access, especially internet connectivity. In eight of the ten initiatives (see figure 
1) the focus is on access to technology, particularly connectivity and content. The EGDI's OSI and EPI sub-indexes emphasis content availability.

ITU's IDI is the dominant global source of data for most research and for six of the ten initiatives. GMSA collects a substantial amount of complimentary data. Like ITU, Eurostat's DESI and the Australian DII are based on data collected by national statistical agencies, i.e., domestic sources, which also form the basis of the ITU and UNESCO indicators and statistical databases [11,57].

For technology types and affordability, the GSMA report and MIC initiative includes a large number of statistics [53], while UNESCO is the source of skills related indicators. In relation to the availability of public sector online service offers, UNDESA's biannual EGDI survey is the main source [12]. The European ICT Household Survey offers relatively rich data [28], and statistical agencies in countries like Australia, Brazil and South Africa also collect and segment data in similar ways.
The primary focus of the majority of indicators, in the assessed initiatives, is on access to fixed and mobile internet and telephony. As a primary communication technology means for internet data transfer, telephony have largely been replaced by mobile and fiber-optic infrastructure. A fact illustrated by the EGDI excluding fixed-line telephony for the first time is 2020 edition [11]. Of secondary interest is the quality of access, as defined by bandwidth, up- and download speeds. Interestingly, indicators attempting to measure relative affordability and technology solutions such as fiber-optic and $3 \mathrm{G}, 4 \mathrm{G}$ and $5 \mathrm{G}$ are generally found in initiatives from the private sector, NGOs and academia. Depending on the specific focus, within the larger theme of digital inclusion, of each of the ten initiatives, a number of different topical indicators emerge. This includes different user-groups and urban-rural divides, as well as financial inclusion, entrepreneurship and innovation.

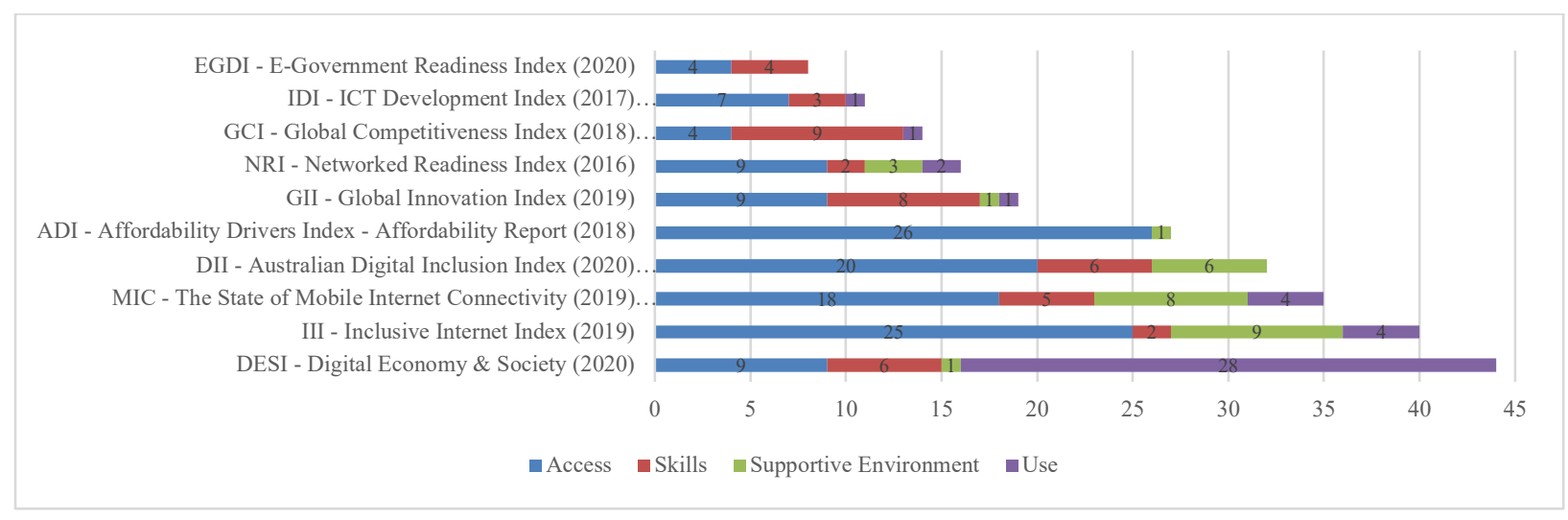

Figure 1. Dominant indicators in ten key initiatives monitoring the digital inclusion of marginalised communities by cluster (only indicators related to the four main clusters included) (Source: Adapted by author from [8])

\section{Weaknesses of current indicators to support strategic and practical decision making facilitating digital inclusion}

To identify any potential weaknesses of the indicators used in the ten cases assessed, it is important to remember that to effectively measure digital inclusion, indicators associated to four key clusters are essential $[8,50]$. That is: access to electricity, the internet, devices and quality of that access; traditional and digital skills and competences including critical thinking and entrepreneurship; use to measure actual value creation and digital inclusion of marginalised communities, and; the supportive conditions, including affordability, identification, financial inclusion, trust and security.

Continuous measurement and monitoring are essential to ensure that the appropriate actions are taken to eliminate the digital divide, and increase the digital inclusion of marginalised communities. An appropriate set of indicators will enable effective monitoring and guide the efforts, aid policy and decision-makers at a strategic and operational level $[8$, $22,26]$ and help monitor the UN SDGs objective of leaving no one behind by 2030 [54].

As preconditions for digital inclusion, access, skills and competencies constitute the main clusters of the assessed initiatives. As earlier identified, access to the internet is features 127 indicators, making it the a dominate focus area in eight of initiatives assessed, bar DESI and GCI. Access to the internet and associated 
technologies is generally seen as precondition for digital inclusion, thereby important to advance in a majority of the cases assessed. All ten cases seem to recognise that access alone is not enough to facilitate digital inclusion. That is, without the opportunity, skills to use ICT or the financial means to access ICTs, digital exclusion will persist. For example, the Covid19 related lockdowns have led to the unintentional exclusion of people from social security services and education [45]. Even pre-pandemic, free public hotspots in Johannesburg were used less frequently by women due to fearing crime, and girls are occasionally being physically prevented from accessing WiFi by boys [6]. Usage and a supportive environment are therefore essential clusters for measurement of digital inclusion in marginalised groups.

Skills, in turn, refer to a person's ability to increase the benefits gained from using digital technologies and avoid the downsides that can ensue from digital engagement [61]. There are multiple components to necessary skills, including reading, writing, and numeracy, but also critical thinking, problem solving, creativity and entrepreneurship. In an increasingly digital society basic digital literacy is a skill increasingly required. To categorise and measure digital skills a multitude of frameworks have been proposed [24, 61]. Generally, the ten cases reflect this and seemingly agree that technical skills are but one component facilitating digital inclusion. For instance, the European Commission's Digital Competencies Framework (DigComp 2.0) emphasise: information and digital literacy, communication and collaboration, digital content creation, problemsolving, and safety - including protecting ones privacy and personal data from abuse [58]. The majority of the 62 different skills related indicators used in the ten cases analysed, are associated with traditional literacy skills like reading, writing and math. Only nine indicators cover STEM, eight are on basic digital skills and one addresses critical thinking. The focus on traditional literacy may be the result of data availability, with UNESCO and ITU being the two dominant data sources.

In relation to the supporting environment, access to financial services and legally valid identities feature less frequently in the initiatives assessed and could be deemed a weakness, as roughly half the global population does not yet use the internet. While 47 different indicators can be linked to the supportive environment cluster, 19 indicators are related to the affordability of the internet and ICT. These themes are well covered but concentrated in initiatives like the ADI, III and GCI, from non-profit and private sector stakeholders. Two initiatives, the IDI and GCI, do not include any indicators related to the supporting environment. The III, MIC, DII and the EGDI are the four initiatives with the highest relative number of indicators related to the supporting and enabling aspects of digital inclusion (see figure 1).

Various forms of internet and ICT usage is the focus of 50 indicators. With the exemption of the ADI, DII and EGDI, the other seven initiatives cover usage. The European DESI is the initiative with the highest proportion of indicators assessing usage accounting for the vast majority of the 50 indicators, followed by the III and the MCI (see figure 1). The limited focus on usage is unfortunate because it is the use of digital infrastructure and devices to access digital content which equates digital inclusion, not the theoretical and potential use. Similarly, it is use which creates the value for the individual and generates return on public and private investment in infrastructure, skills and supporting initiatives to promote digital inclusion, eliminating various forms of digital and other socioeconomic divides [35, 43, 44].

As access to and reliability of technology, not least the internet, is partially determined by the geographical location of the potential user, the segmentation of data for various indicators is important in order to ascertain any potential digital divide and exclusion [8, 50]. Similarly, skills vary greatly by country, gender, age, geographical location and socio-economic circumstances. Skills in turn impact ability to both afford ICT access then to derive benefit. Socio-economic circumstances are therefore closely connected to digital inclusion, particularly for lower-income groups [8, 24, 50].

In relation to the geographical coverage, the nine international measurement initiatives on related to digital inclusion do not cover the world in equal measure. Low and medium-income countries in northcentral Africa, Central Eurasia and the Middle East are the least covered. Based on statistical data in the nine international cases analysed, these are not only the countries with the proportionally largest digitally excluded communities domestically, but also the countries with the widest gap separating them from the world's most digitally advanced and inclusive societies (figure 2), thus supporting past observations $[8,32,41,50]$. In short, the nine global initiatives have the least focus on countries with the largest digital exclusion, with the Australian initiative naturally focusing exclusively on Australia. 


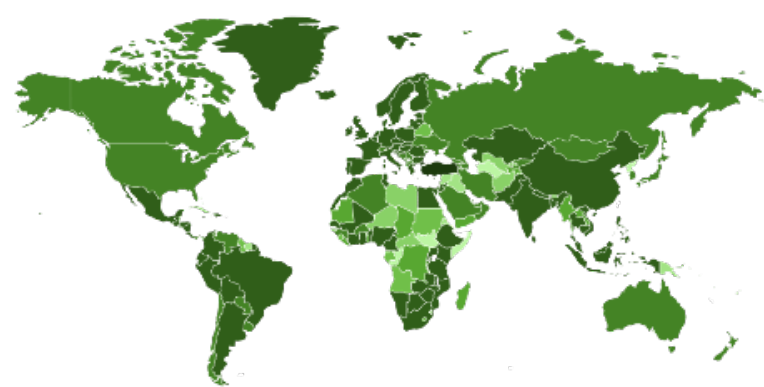

Figure 2. Geographical coverage of measurements initiatives covering digital inclusion. Key: The darker the colour the higher the number of initiatives covering the country (Source: Adapted by authors from [8])

The majority of existing digital inclusion indicators focus on cross-country comparisons in relation to access and skills. The lack of sub-national levels limits the value of current indicators for policy and decision makers who cannot prioritise or target initiatives to specific geographical communities. International initiatives could review their approach by identifying national sources of location and usersegmented data, for instance in Australia, Brazil, South Africa, and Europe where such segmented data is at least partially available.

Only a limited number of indicators focus on the value created by the actual use of acquired skills to benefit from ICT. Other than affordability, themes such as supportive elements of legally valid identification, access to financial services, trust in technology, or physical safety to access e.g. public $\mathrm{WiFi}$ that influence the digital inclusion of marginalised communities are largely missing $[6,8$, 50].

Considering the importance of socio-economic factors, age and gender to digital inclusion, it is surprising that only 7 of 303 indicators are related to different user-groups, and these refer specifically to gender. The majority of international attempts to measure the availability and adoption of ICT does not segment indicators on different types and groups of users, let alone their physical location in a given country. While some indicators on gender equality are identified, the majority do not differentiate between different user-groups. The DESI and DII stands out as positive examples in relation to various ways of usersegmentation. The EGDI also does so but only for certain content types in the OSI and EPI sub-indexes [1]. Without segmenting data with respect to gender, age, income and educational level, the extent to which specific user-segments and marginalised communities are digitally included cannot be assessed over time and have limited value to decision makers.
While countries do collect user and location segregated data on an annual basis or in connection with regular population censuses $[8,45]$, the comparability of national indicators is nonetheless unclear. For instance, children, adolescents and young adults are defined differently globally. In Brazil, adolescents are considered individuals aged 14 or older, whereas Eurostat use 15 as the cut-off age. While the legally defined age of adulthood is often defined as 18 globally, young adults are often statistically grouped with adolescents who are legally defined as minors and therefore have different legal rights and responsibilities [45]. Applicable indicators may therefore measure digital inclusion in a general sense, but are often of limited value as a measure for the inclusion of marginalised groups and communities and in turn as a tool for policy makers to base their decisions and priorities upon.

\section{Conclusion}

Therefore, how do the ten initiatives measuring elements of digital inclusion perform in light of the challenge laid down by the High-Level Panel on Digital Cooperation to develop a global framework for measuring digital inclusion and the SDG 2030 Agenda? [32, 54] With respect to the indicators of digital inclusion or inequality are used in key global measuring initiatives (RQ1), the focus is generally on national or cross-country comparisons of access, skills and some basic online activities. In order, to support strategic and practical decision making facilitating digital inclusion ( $R Q 2)$, this focus should be expanded beyond mere access to electricity, the internet and devices, to include the affordability (e.g. price related to GDP per capita) and quality of such access (e.g. connectivity type and bandwidth), and their point of access (e.g. home, work, third party hotspots).

Related to skills, the length of education and traditional skills which currently dominate measurements of digital literacy are of value, but this does not fully reflect the skills and competences required in an increasingly digital society. Digital transformation of society and the workplace requires that traditional competences should ideally be expanded to include additional digital competences (e.g. use of internet, various tasks and even coding), critical thinking and entrepreneurship (incl. STEM).

Unfortunately, access to ICT and the ability to use it does not automatically lead to the inclusion of excluded or marginalised individuals and communities. Whether it is telecommunication infrastructure, skills development, or digital content, services and products, the benefits of a given investment is dependent on use. It would therefore be 
worth including indicators which monitor and measure the use of public and private online service offers to ensure the further inclusion of marginalised communities, and that socio-economic value is created from investment in ICTs (e.g. eBanking, eCommerce, government online services, eLearning, social media).

Given that digital inclusion is not a forgone conclusion, a number of supportive conditions are required. To eliminate current digital divides, indicators related to the relative affordability of internet access and devices should be considered. Similarly, indicators assessing the ability of individuals to identify themselves, the level of their financial inclusion, the degree of trust they have in in technology and online service provision, as well as security in both the physical and digital world, should all be considered. Not least because these factors directly impact on the likelihood of people actively seeking out digital opportunities and thus inclusion.

The initiatives analysed in this paper are largely confined to national comparisons and only have limited differentiation between different user groups and activities. To facilitate more targeted and refined decisions and resource allocation, geographical and user segmentation is recommended. Segmentation would enable more refined monitoring of communities at risk of digital exclusion. The ability to aggregate and disaggregated data would help optimise knowledgebased decision making, via pinpointing communities needing assistance and areas to prioritise. Geographical segmentation at national and subnational levels should be considered, while user segments should ideally include gender, specific age groups, income and educational attainment levels and employment type (e.g. "white" and "blue" collar work), as seen in e.g. DESE or DII.

While this analysis is limited to ten initiatives measuring digital inclusion, many more exist. It would be relevant to complement the findings of this analysis with more research on national approaches to data collection and indicators related to digital inclusion. For instance, the Western Balkan countries are currently aligning their national approaches to that of the European DESI. National statistical agencies in middle income countries like Brazil and South Africa, or PEW in the USA, have long traditions of collecting similar indicators to those assessed in this paper. It would also be relevant to explore the feasibility and practicality of collecting more segmented indicators, to identify complimentary, collaborative and costefficient approaches to data collection. This could include partnership models between national statistical agencies, the telecommunication sector, international organisations and academia. These are themes which the author will pursue in future research. Such research would hopefully address the call by the UN Secretary General Antonio Guterres, the UN High-Level Panel and the gaps and challenges identified by this paper and past research.

\section{References}

[1] UNDESA - United Nations Department of Economic and Social Affairs 2016. E-Government Readiness Survey Database. United Nations.

[2] Affordability Drivers Index (ADI): 2018. .

[3] Akca, H. et al. 2007. Challenge of rural people to reduce digital divide in the globalized world: Theory and practice. Government Information Quarterly. 24, 2 (2007), 404-413.

[4] Alhomod, S.M. et al. 2015. i-Voting and verifiability in Switzerland. Government Information Quarterly. 2017, 2 (2015), 58. DOI:https://doi.org/http://dx.doi.org/10.1016/j.giq. 2009.06.002.

[5] Australian Digital Inclusion Index (ADII): 2020. https://digitalinclusionindex.org.au/. Accessed: 2021-03-15.

[6] Backhouse, J. and Chauke, H. 2020. Development Impacts of Free Public Wi-Fi in Johannesburg. Handbook of Research on Managing Information Systems in Developing Economies. IGI Global. 374-395.

[7] Collier, D. and Mahoney, J. 1996. Insights and pitfalls: Selection bias in qualitative research. World Politics. 49, 01 (1996), 56-91.

[8] DFS - Digital Future Society 2019. Measuring the margins: A global framework for digital inclusion.

[9] Digital Accessibility Rights Evaluation (DARE) Index: 2020. https://g3ict.org/digital-accessibilityrights-evaluation-index/. Accessed: 2021-09-02.

[10] van Dijk, J.A.G.M. 2013. A theory of the digital divide. The digital divide: the internet and social inequality in international perspective.

[11] E-Government Development Index (EGDI): 2020.

[12] E-Government Readiness Survey Database: 2018. $\% 7 B U N D E S A$ - United Nations Department of Economic and Social Affairs, 2016 \#778\%7D. Accessed: 2018-11-16.

[13] Erwin, E.J. et al. 2011. Understanding qualitative metasynthesis: Issues and opportunities in early childhood intervention research. Journal of Early Intervention. 33, 3 (2011), 186-200.

DOI:https://doi.org/10.1177/1053815111425493.

[14] EU Kids Online: 2020. http://globalkidsonline.net/eu-kids-online/. Accessed: 2021-09-02.

[15] Gauld, R. et al. 2010. Do they want it? Do they use it? The 'Demand-Side' of e-Government in Australia and New Zealand. Government Information Quarterly. 27, 2 (2010), 177-186. DOI:https://doi.org/http://dx.doi.org/10.1016/j.giq. 2009.12.002.

[16] Gender Inequality and COVID-19 Crisis Dashboard: 2021. 
http://hdr.undp.org/en/content/gender-inequalityand-covid-19-crisis-dashboard. Accessed: 202109-02.

[17] Gender Social Norms Index (GSNI): 2020. http://hdr.undp.org/en/gsni. Accessed: 2021-0902 .

[18] Global Innovation Index (GII): 2020. https://www.globalinnovationindex.org/aboutgii\#keyfindings. Accessed: 2021-03-15.

[19] Global Kids Online: http://globalkidsonline.net/. Accessed: 2021-09-02.

[20] Global Preparedness and Vulnerability Dashboards: 2021. Global Preparedness and Vulnerability Dashboards. Accessed: 2021-09-02.

[21] He, W. et al. 2021. Information technology solutions, challenges, and suggestions for tackling the COVID-19 pandemic. International journal of information management. 57, (2021), 1-8.

[22] Heeks, R. 2006. Understanding and measuring eGovernment: international benchmarking studies. UNDESA workshop, "E-Participation and EGovernment: Understanding the Present and Creating the Future”, Budapest, Hungary. (2006), 27-28.

[23] Helbig, N. et al. 2009. Understanding the complexity of electronic government: Implications from the digital divide literature. Government Information Quarterly. 26, 1 (2009), 89-97.

[24] Hilding-Hamann, K.E. et al. 2008. Supporting Digital Literacy: Review of measurement tools and indicators (Topical Report 2).

[25] Human Development Index (HDI): 2020. http://hdr.undp.org/en/content/humandevelopment-index-hdi. Accessed: 2021-09-02.

[26] Huovila, A. et al. 2019. Comparative analysis of standardized indicators for Smart sustainable cities: What indicators and standards to use and when? Cities. 89, (2019), 141-153.

[27] ICT Development Index (IDI): 2017. .

[28] ICT usage in households and individuals (ICTUHI): 2020. .

[29] ILO; et al. 2020. Impact of COVID-19 on people's livelihoods, their health and our food systems. WHO.

[30] Inclusive Internet Index (III): 2021 https://theinclusiveinternet.eiu.com/. Accessed: 2021-03-15.

[31] Jaeger, P.T. et al. 2012. The intersection of public policy and public access: Digital divides, digital literacy, digital inclusion, and public libraries. Public Library Quarterly. 31, 1 (2012), 1-20.

[32] Key economic forum in Russia: New technology a 'vector of hope' but also 'a source of fear' says Guterres: 2019.

https://news.un.org/en/story/2019/06/1040051. Accessed: 2019-07-01.

[33] Martins, J., Meyerhoff Nielsen, M., Soares, D., Barbosa, L. 2019. A Longitude Analysis of the UNDESA E-Government Surveys. New York, Guimaraes: UNDESA, UNU-EGOV, pp. 1-26.
[34] Meyerhoff Nielsen, M. et al. 2018. Emperical Analysis of the Current Digital Divides since 2010. ICEGOV conference proceedings (New York, 2018), 616-625.

[35] Meyerhoff Nielsen, M. Online usability and value creation: Comparing the usability criteria and governance models in Denmark, Portugal, UK and USA. dms - der moderne staat. Digital transformation in the public sector: From design to effect.

[36] Museums, Libraries, and 21st Century Skills: 2021. https://www.imls.gov/issues/nationalinitiatives/museums-libraries-and-21st-centuryskills. Accessed: 2021-03-15.

[37] Muthu Kumar, S. et. al., S. 2017. Digital Inclusion Index: A Measurement of ICT Advancements in Bahrain \& GCC. International Journal of Computing and Network Technology. 05, 02 (2017), 59-64.

DOI:https://doi.org/10.12785/ijent/050203.

[38] Negreiro, M. 2015. Briefing Bridging the digital divide in the EU. December (2015).

[39] Nielsen, M.M. et al. 2018. Empirical analysis of the current digital divides since 2010. ACM International Conference Proceeding Series (2018).

[40] Nielsen, M.M. et al. 2018. Empirical analysis of the current digital divides since 2010. ACM International Conference Proceeding Series (2018).

[41] Nielsen, M.M. and Makpor, M.E. Digital inclusion and gender-associated indicators : A critical review of post- 2010 literature.

[42] Norris, D.T. and Conceição, S. 2004. Narrowing the digital divide in low-income, urban communities. New directions for adult and continuing education. 2004, 101 (2004), 69-81.

[43] OECD - Organisation for Ecoonomic Cooperation and Development 2019. Strengthening Digital Government.

[44] Panagiotopoulos, P. et al. 2019. Public value creation in digital government. Elsevier.

[45] Pelter, Z., Byrne, J., Meyerhoff Nielsen, M., Makpor, M.E. 2021. Government digital services and children:

[46] Philip, L. et al. 2017. The digital divide: Patterns, policy and scenarios for connecting the "final few" in rural communities across Great Britain. (2017). DOI:https://doi.org/10.1016/j.jrurstud.2016.12.002

[47] Pick, J. and Sarkar, A. 2016. Theories of the digital divide: Critical comparison. Proceedings of the Annual Hawaii International Conference on System Sciences. 2016-March, (2016), 3888-3897. DOI:https://doi.org/10.1109/HICSS.2016.484.

[48] Ragnedda, M. and Muschert, G.W. 2013. The digital divide: The Internet and social inequality in international perspective. Routledge.

[49] Sandelowski, M. et al. 1997. Focus on qualitative methods. Qualitative metasynthesis: issues and techniques. Research in nursing \& health. 20, 4 
(1997), 365-371.

DOI:https://doi.org/10.1002/(SICI)1098-

240X(199708)20:4<365::AID-NUR9>3.0.CO;2-E.

[50] Sey, A. and Hafkin, N. 2019. Taking stock: Data and evidence on gender equality in digital access, skills and leadership. United Nations University, Tokyo. (2019).

[51] Singh, J. and Singh, J. 2020. COVID-19 and its impact on society. Electronic Research Journal of Social Sciences and Humanities. 2, 1 (2020), 168172.

[52] Srinuan, C., Rohman, I.K., Srinuan, P., and Bohlin, E. 2010. Digital divide in ASEAN countries: Explaining the gap. Competitiveness of the ASEAN Countries: Corporate and Regulatory Drivers. 153-172.

[53] State of Mobile Internet Connectivity 2019: 2019. https://www.mobileconnectivityindex.com/. Accessed: 2021-03-15.

[54] Sustainable Development Goals - 17 Goals to Transform Our World: 2015.

http://www.un.org/sustainabledevelopment/sustain able-development-goals/.

[55] The 2020 Global Multidimensional Poverty Index (MPI): 2020. http://hdr.undp.org/en/2020-MPI. Accessed: 2021-09-02.

[56] UNDESA - United Nations Department of Economic and Social Affairs 2012. E-Government Survey 2012: E-Government for the people. United Nations.

[57] Union, I.T.U.-I.T. 2017. Worlds Telecommunication / ICT Indicators Database. ITU - Internet Telecommunications Union.

[58] Vuorikari, R. et al. 2016. DigComp 2.0: The Digital Competence Framework for Citizens.

[59] WEF - World Economic Forum 2018. Global Competitiveness Report (GCR).

[60] World Bank Group 2016. Digital Dividends.

[61] World Benchmarking Alliance 2019. Digital Inclusion Benchmark: Scoping Report.

[62] Yasir, A. et al. 2020. Modeling impact of word of mouth and E-government on online social presence during COVID-19 Outbreak: a multimediation approach. International journal of environmental research and public health. 17, 8 (2020), 2954.

[63] Yin, R.K. 2013. Case study research: Design and methods. Sage publications. 